\title{
Post-Natal Death at 16-20 Weeks Gestation
}

National Cancer Institute

\section{Source}

National Cancer Institute. Post-Natal Death at 16-20 Weeks Gestation. NCI Thesaurus.

Code C114870.

A fetus of 16-20 weeks gestational age that shows signs of life at birth but dies after delivery. 